\title{
Multizone Model Study for DI Diesel Engine Running on Diesel-Ethanol-Biodiesel Blends of High Ethanol Fraction
}

\author{
D. B. Hulwan ${ }^{1 *}$ and S. V. Joshi ${ }^{2}$ \\ ${ }^{1}$ Faculty of Mechanical Engineering, Vishwakarma Institute of Technology, \\ Pune, India. \\ ${ }^{2}$ Faculty of Mechanical Engineering, PVPIT Sangli, \\ Maharashtra, India \\ "Email: dattatray.hulwan@ vit.edu \\ Phone: +919822667480
}

\begin{abstract}
A multizone combustion model for closed cycle of a DI diesel engine is developed to interpret the experimental investigations on the utilization of diesel-ethanol-biodiesel blends of high ethanol fraction (DEB blends). A computer-based programming for engine process simulation is developed in MATLAB. The model is validated with the experimental values of cylinder pressure and heat release rate. Important information related to fuel injection and combustion inside the combustion chamber, is revealed through the model prediction which is normally difficult to get from the experiments. Model prediction shows that the rate of fuel evaporation is higher for DEB blends, than diesel fuel at any instant of time. The fuel combustion is started late for DEB blends compared to diesel fuel, however, once the combustion is started the burning rate is higher than the diesel fuel. The droplet size (Sauter mean diameter) is decreased for DEB blends which indicate improved fuel atomization. The mean temperature in the zone is significantly lower for DEB blends compared to diesel fuel. The equivalence ratio in the zone is decreased for DEB blends proving that engine runs leaner. The equivalence ratio trend is not uniform as it depends on the combination of the rate of fuel evaporation, rate of air entrainment and rate of burning. Soot density is remarkably decreased, and NOx formation is also drastically reduced for DEB blends at different instant of time. The predictions help to interpret the experimental results for DEB blends and its comparison with diesel fuel.
\end{abstract}

Keywords: Multizone combustion model; DEB blends of high ethanol fraction.

\section{INTRODUCTION}

Engine development is driven by the stringent regulation on exhaust emissions and higher fuel efficiency to reduce the fuel consumption. It is also required to minimize the excessive use of fossil fuels and dependence on the petroleum resources as it is obtained from limited reserves. This will help to reduce global environmental degradation and health hazards. These facts led research on alternative renewable fuels. Among the proposed alternative fuels biodiesel and ethanol (blends with diesel) have received much attention in recent years for diesel engines. Biofuels and diesel fuel blends can be used on existing engines to achieve both the environmental and energy benefits. The modern techniques such as, common rail systems, fuel injection control strategies, exhaust gas recirculation, exhaust gas after treatment etc helped in the development of 
cleaner diesel engines [1, 2]. Researchers have focused their interest on the domain of fuel related techniques such as, the use of alternative fuels, especially for the reduction of emissions, [3-7], or oxygenated fuels that show the ability to reduce particulate emissions $[8,9]$.

Alternative fuels, basically liquid fuels, have been tested on the diesel engines by forming its blends with the diesel fuel in different proportions. There are number of studies having the experimental investigations on the utilization of various blends of diesel and alternative fuels like ethanol and biodiesel. However, there is absolute scarcity of the theoretical studies giving the information about the phenomenological changes happening inside the combustion chamber when the engine runs on the blends. The purpose of this work is to capture the information in the combustion chamber which is difficult to obtain experimentally.

\section{EXPERIMENTAL SET UP}

The combustion characteristics of a three-cylinder diesel engine were determined at $1500 \mathrm{rpm}$, at low load of 0.2 MPa BMEP and high load of 0.6MPa BMEP. The details of the engine and the experimental procedure were reported in previous paper [10]. The experiments were performed for the following blends:

a) Blend D- $50 \%$ diesel, $30 \%$ ethanol and $20 \%$ biodiesel; by volume, $\mathrm{D} 50 / \mathrm{E} 30 / \mathrm{B} 20$

b) Blend E- $50 \%$ diesel, $40 \%$ ethanol and $10 \%$ biodiesel; by volume, D50/E40/B10

c) Diesel: $100 \%$ diesel

The experiments were conducted to collect the pressure crank angle data (P- $\theta$ diagrams) at the various operating conditions mentioned above. A computer-based program is developed in MATLAB for the simulation of engine processes. The model consists of the calculations for the important processes and sub models, step by step to reveal phenomenon in the combustion chamber. The processes considered are fuel injection process, Fuel jet break up point and initial angle, division of fuel spray into zones, their development and air entrainment, fuel droplets evaporation, combustion rate sub-model and ignition delay period, heat transfer (cylinder wall heat loss) submodel, combustion-chemical equilibrium to determine species concentration, net soot formation sub-model, nitric oxide formation sub-model, conservation of mass and energy equations and state equations.

\section{MATHEMATICAL MODELLING}

There are different types of engine simulation models used for diesel engines such as zero-dimensional single-zone models, quasi-dimensional multi-zone models and multidimensional models. Zero-dimensional, single-zone models assume [11-13] that the cylinder charge is uniform in both composition and temperature, at all time during the cycle. It is shown that the engine performance can be predicted accurately with the help of calibrated and validated single zone models. It also gives results with high computational efficiency. However, single zone models are not capable of accounting spatial variation in mixture composition and temperature, spray evolution, which is required to predict exhaust emissions. Compared to single zone models, multidimensional models, like KIVA [14-19] divide the space of the cylinder on a fine grid, thus providing a substantial amount of special information. However, it still 
requires phenomenological sub-models describing fuel spray processes. Furthermore, its results depend on the assumed initial or boundary conditions. It also has limitations like computational time and storage constraints.

On the other hand, quasi-dimensional multi-zone models can be effectively used to model diesel engine combustion systems. It is an intermediate step between zerodimensional and multi-dimensional models and combines some of the advantages of zero-dimensional models and multi-dimensional models. Mass balance, energy balance and species equations are solved in this technique without going for explicit solution of the momentum equation. These models are capable of giving spatial information required to predict emissions compared to single zone models and require considerably less computing time compared to multi-dimensional models. These models have been an active area of research since the early heat release studies [20] and the two-zone combustion model [21]. The multi-zone models to date have followed the framework proposed by Hiroyasu and others [22-25]. This consists of dividing the spray into the zones in the radial and spray penetrating directions and tracking the evolution of the zones over time as shown in Figure 1.

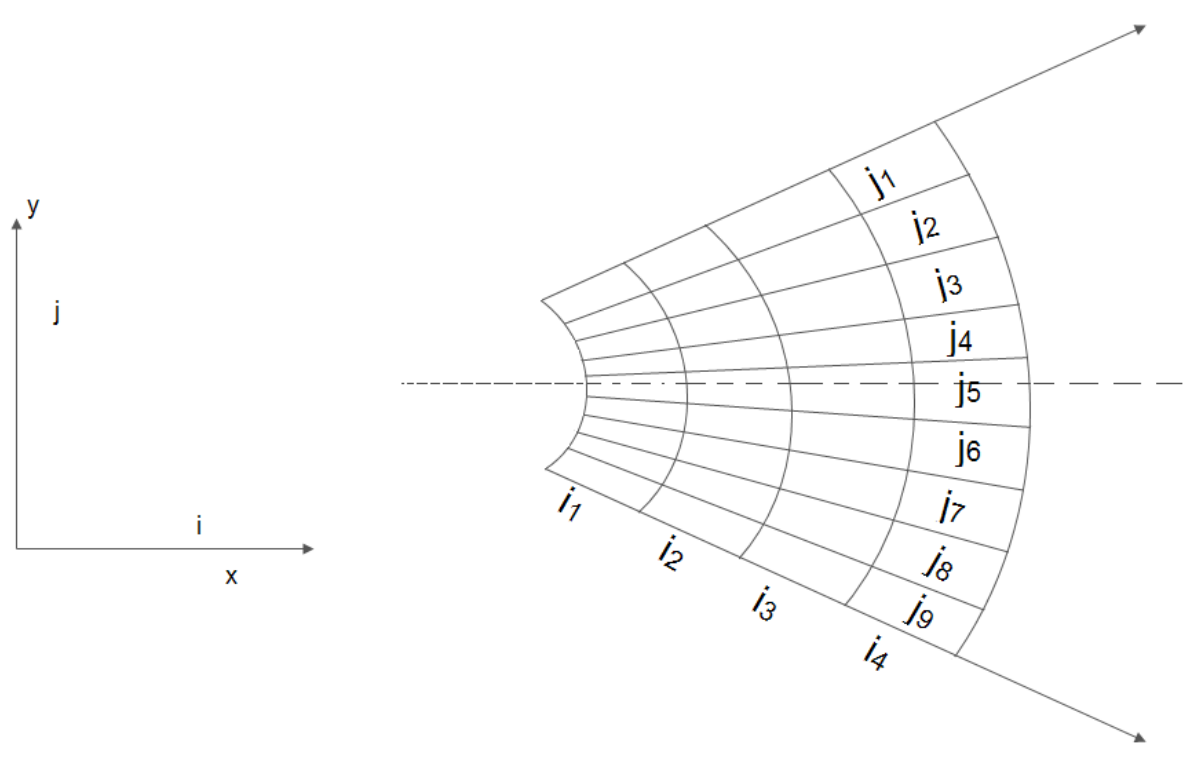

Figure 1: Zone formation at one of the time steps.

Thus, multizone model has the number of advantages over the other models. The multizone model consists of the calculations for the important processes and sub models step by step as mentioned in [26-28].

\section{RESULTS AND DISCUSSION}

DI diesel engine multi zone simulation model results at $1500 \mathrm{rpm}$ and at loads of 0.6 and 0.2 MPa BMEP are discussed in this section. The purpose of this theoretical analysis is to find the necessary relevant information to be used for the justification of the experimental results. Initially the model is validated by comparing its results of cylinder pressure, net heat release rate and mean temperature in the cylinder with the experimental results. The rate of fuel evaporation, rate of fuel burning, and atomization characteristics of diesel fuel and DEB blends predicted by the model are then analyzed 
to see the effects of widely differing properties of DEB blends. Various pictures of the spray at different instants of time for temperature, equivalence ratio, soot density and NO concentration are also taken. The plots are taken at $7^{\circ}$ BTDC (before wall impingement), and $3^{\circ}$ ATDC (after wall impingement). In addition to this these values are also analyzed after every calculation time steps. The analysis reveals the physical mechanisms and showed how the significantly different physical properties of DEB blend; affect the spray formation and thus, the combustion mechanism and related formation of pollutant emissions.

\section{P- $\theta$ Diagrams}

Graphs (a) to (f) from Figure 2, present the comparison of calculated cylinder pressures with the measured ones for diesel fuel Blend D and E. As shown, the trends of calculated pressure match reasonably with the experimentally measured one. The pressure predictions of the model are well within the range considering the limitations of the model. This also indicates that the model simulated the diesel engine cycle closer to the actual one.

The calculated pressure is always higher than that of the experimental one. It is well known fact that the cylinder pressure mainly depends on the start of combustion and rate of combustion (heat release rate).The higher calculated pressure is basically due to high heat release rate predicated by the model. The heat release rate depends on the rate of fuel burning and the later mainly depends on rate of fuel evaporation and amount of air entrained during the time step. Both the parameters are calculated with reasonable assumptions and therefore it's difficult for the model to predict the exact rate of fuel burning. The combustion model used in this study (based on equivalence ratio) over predicted the rate of fuel burning to increase the cylinder pressure and temperature.

\section{Net Heat Release Rate}

Graphs (a) to (f) from Figure 3 gives a comparison, between the net heat release rates derived from the model and the ones obtained by conducting the heat release rate analysis using the experimental pressure diagrams for diesel fuel, blends D and E. As revealed, the theoretical combustion model predicts the heat release rates well within the range considering its limitations of approximate calculations of fuel evaporation rate and air entrainment in the time steps.

It was observed that from Figure 3, the ignition delay for blend D and E is higher than the corresponding one of neat diesel fuel, while its premixed combustion peak is much higher and sharper. It is the lower Cetane index of DEB blends that causes the increase of ignition delay and, so, the increase of 'prepared' fuel (to this end may also help the easier evaporation of ethanol) for combustion after the start of ignition. Lower temperature in the zone of Figure 8, before as well as after initiation of combustion is also the main reason for the increased ignition delay. 


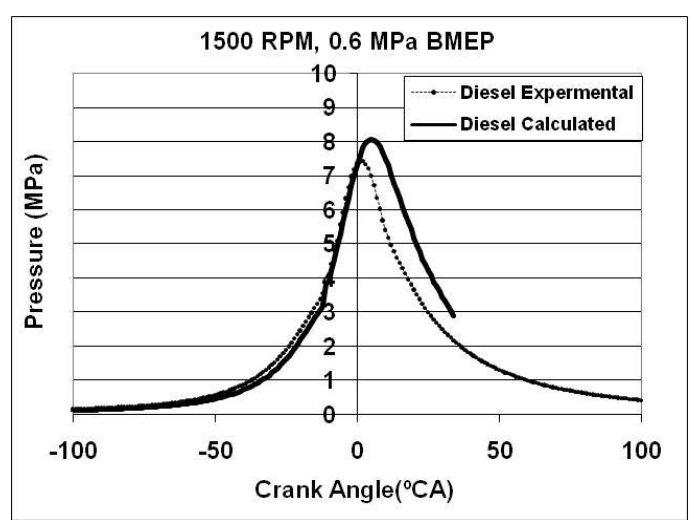

(a)

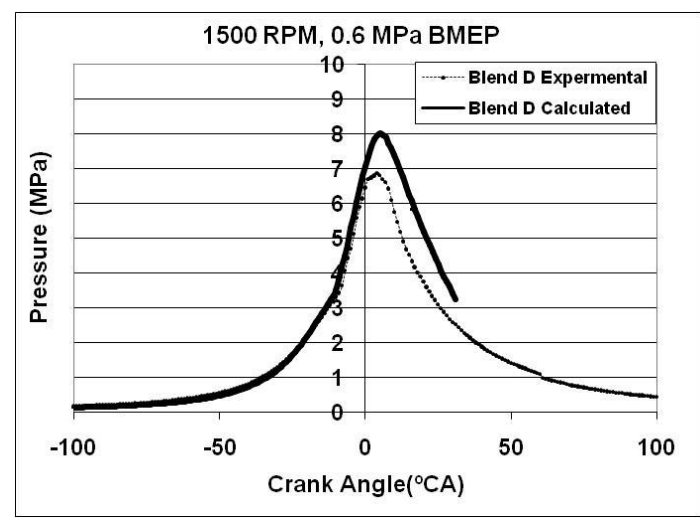

(c)

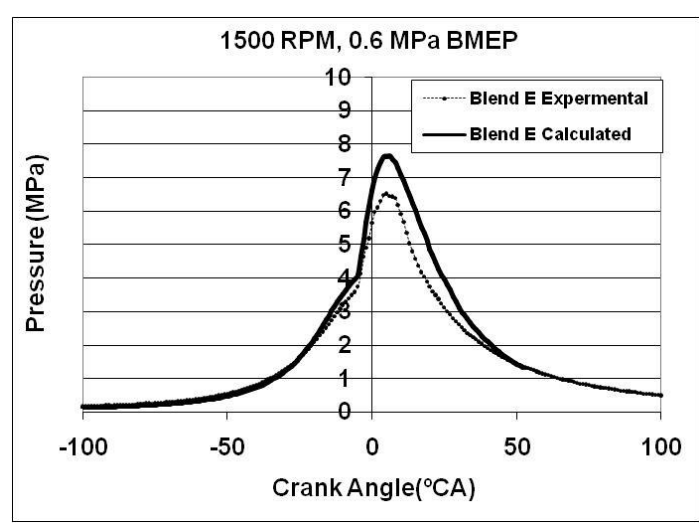

(e)

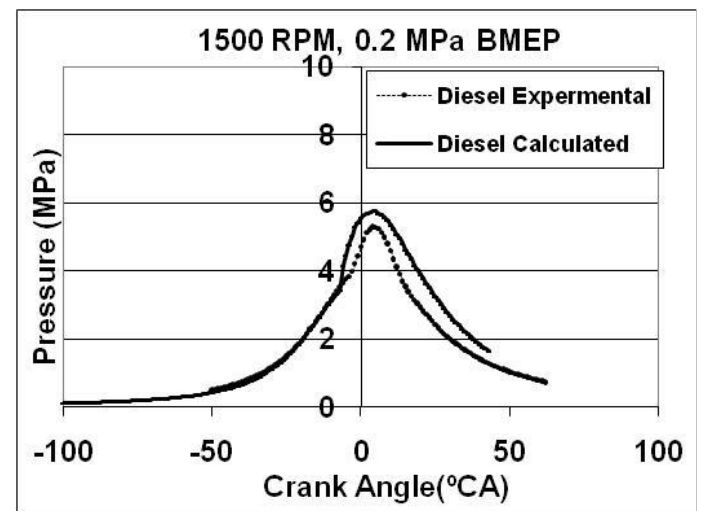

(b)

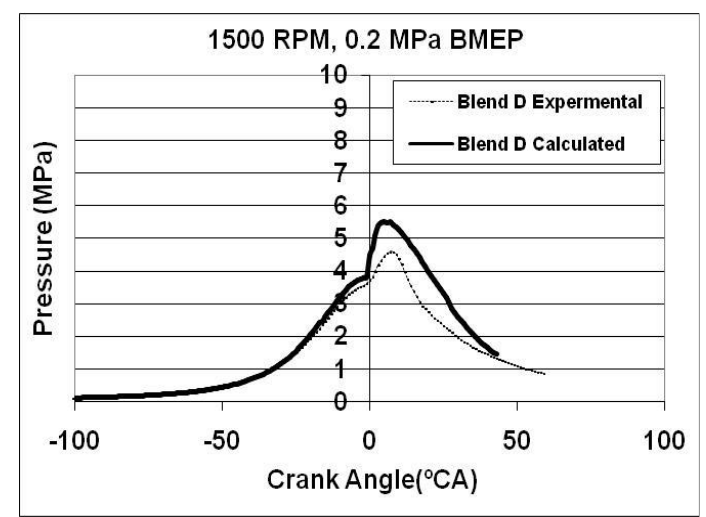

(d)

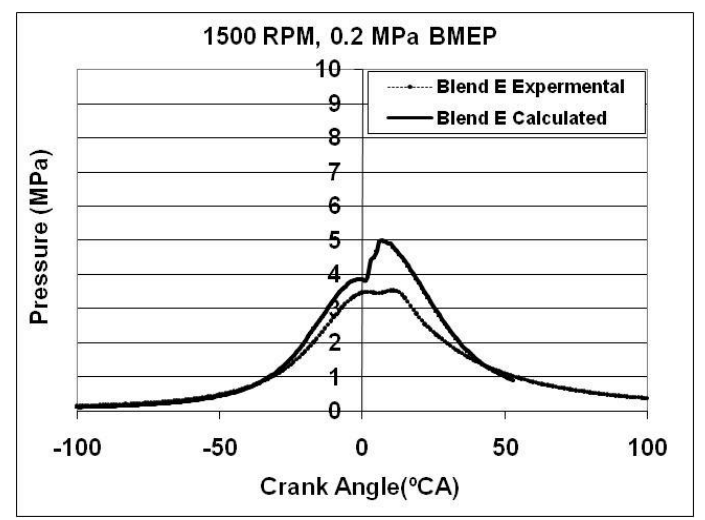

(f)

Figure 2. Pressure crank angle diagram of diesel at (a) $0.6 \mathrm{MPa}$ and (b) $0.2 \mathrm{MPa}$ load; blend $\mathrm{D}$ at (c) $0.6 \mathrm{MPa}$ and (d) $0.2 \mathrm{MPa}$; blend $\mathrm{E}$ at (e) $0.6 \mathrm{MPa}$ and (f) $0.2 \mathrm{MPa}$ load. 


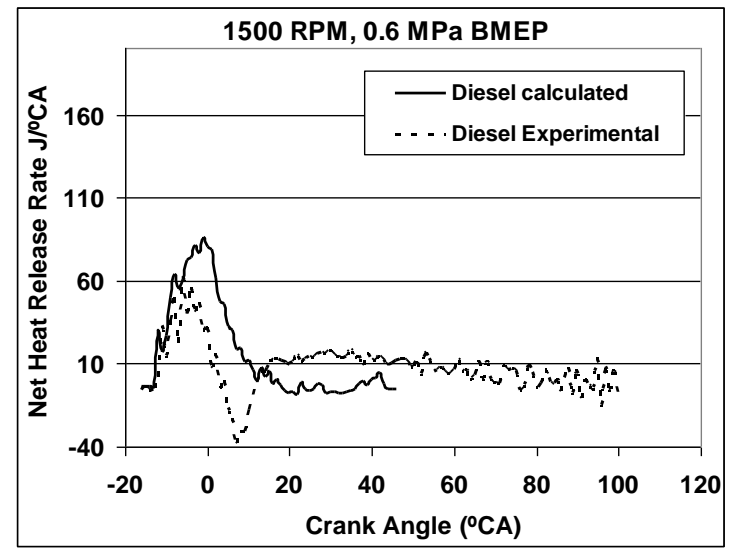

(a)

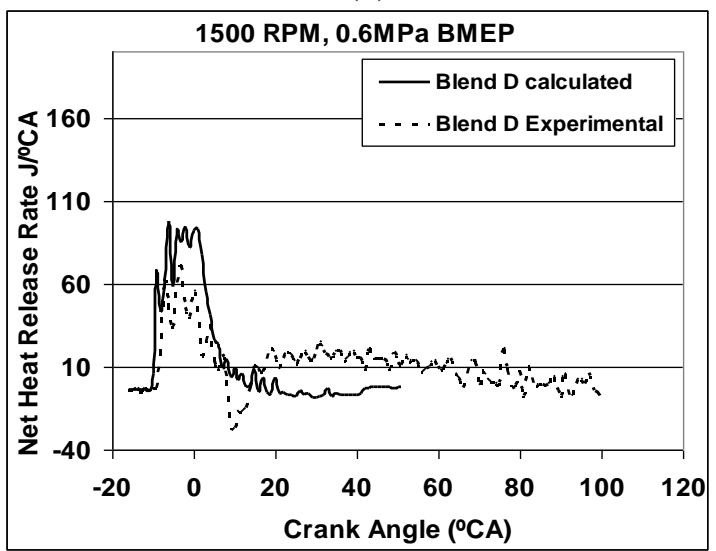

(c)

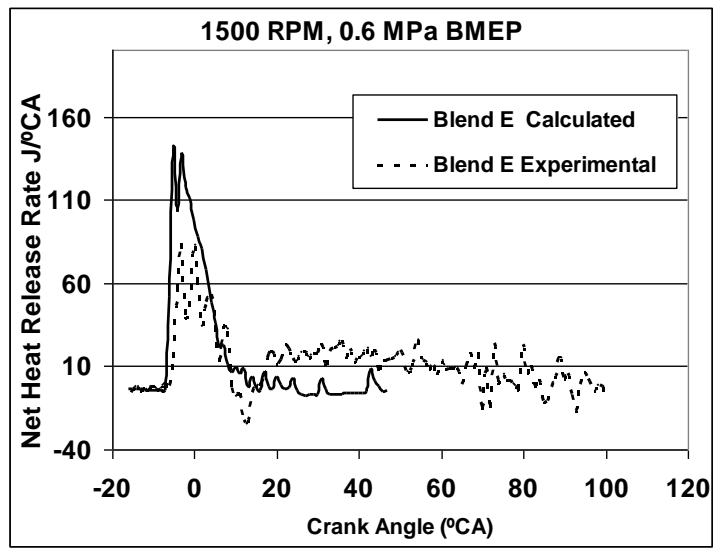

(e)

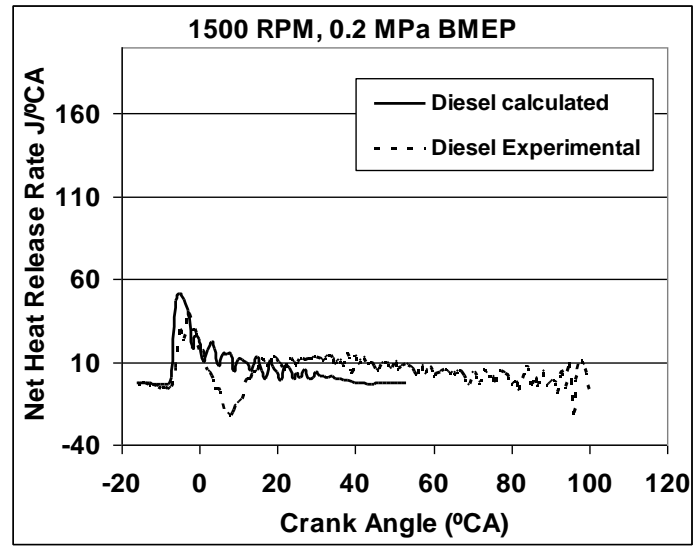

(b)

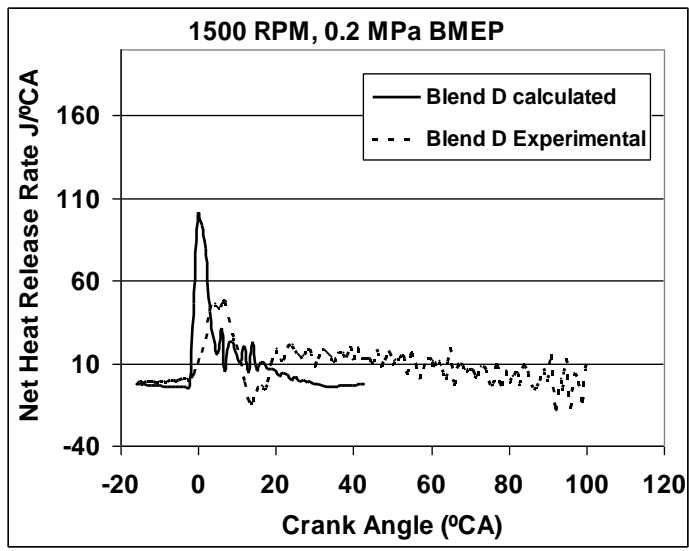

(d)

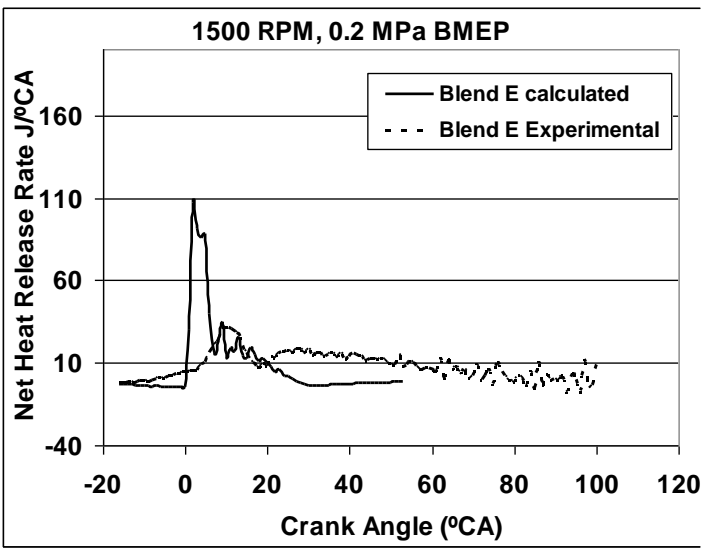

(f)

Figure 3. Net heat release rate of diesel at (a) $0.6 \mathrm{MPa}$ and (b) $0.2 \mathrm{MPa}$ load; blend D at (c) $0.6 \mathrm{MPa}$ and (d) $0.2 \mathrm{MPa}$ load; blend $\mathrm{E}$ at (e) $0.6 \mathrm{MPa}$ and (f) $0.2 \mathrm{MPa}$ load.

\section{Mean Temperature in the Cylinder:}

Graph (a) to (f) from Figure 4 shows the history of the calculated mean temperature in the cylinder, from model and the experimental data for diesel fuel, blends D and E. The sudden increase of the temperature with the initiation of combustion is observed in all cases. Higher temperature values are predicted by the model compared to experimental values. This is mainly attributed to high heat release rate as mentioned above. It is also noticed that model predications showed lower temperature values for DEB blends 
compared to diesel fuel. Generally, the lower temperature values for the blend D and E can be attributed to the engine running a little 'leaner' and possibly to its higher heat of evaporation and lower calorific value. The pressure, temperature and heat release predictions of model well within the range effectively validates that the spray dynamics, fuel droplet evaporation, fuel-air mixing, ignition delay, and combustion sub-models are reasonably working. Therefore, multizone model predictions are used for the physical interpretations of the deviations observed in the experimental results for DEB blends of high ethanol fractions compared to diesel fuel. The information such as rate of fuel evaporation, rate of fuel burning, fuel atomization characteristics, rate of air entrainment in the fuel spray, local temperature, local equivalence ratio, local soot density and local NO concentration in the cylinder is analyzed in the next section. This will help to understand the difference in combustion process of diesel fuel and DEB blends of high ethanol fraction.

\section{Quantity of Fuel Evaporated in the Zone}

The present multi-zone combustion model offers valuable information such as amount of fuel evaporated, amount of fuel burned, local temperatures, local equivalence ratio, then local nitric oxide concentrations and soot densities, at various instants of time. Graph (a) to (b) from Figure 5 shows, for each fuel, the history of the calculated percentage of the evaporated fuel from all zones with respect to the cumulative fuel injected up to the present moment. It can be seen, as expected, that this value is higher for Blend D and Blend E, than diesel fuel case at any instant of time. This is basically due to higher evaporation rate of the ethanol in these blends. The increased rate of fuel evaporation for DEB blends is also attributed to increase of mass diffusivity (fuel in air), reduction in density and viscosity, and improved atomization. The increased rate of fuel evaporation means more fuel available for combustion and improved fuel air mixing. The observed small 'knee' in the curves corresponds to the moment of fuel injection termination where, from then on, the value in the denominator of the cumulative fuel injected remains constant.

\section{Quantity of Fuel Burned in the Zone}

Graph (a) to (b) from Figure 6 shows, for each fuel, the history of the calculated percentage of the burned fuel from all zones with respect to the cumulative fuel injected up to the present moment. It can be seen that the fuel combustion is started late for blend D and E compared to diesel fuel. However, once the combustion is started the burning rate is higher than the diesel fuel. This also indicates that the rate of premixed combustion is increased for blends D and E compared to diesel fuel. This Figure also reveals that the total fuel burned is marginally higher for the blends D and E compared to diesel fuel indicating the improvement in the combustion efficiency for DEB blends of high ethanol fraction. The exact prediction of amount of fuel burned in time step is much difficult because it depends on rate of fuel evaporation, ignition delay, amount of air mixed with fuel, and all these processes are formulated with the reasonable assumptions. 


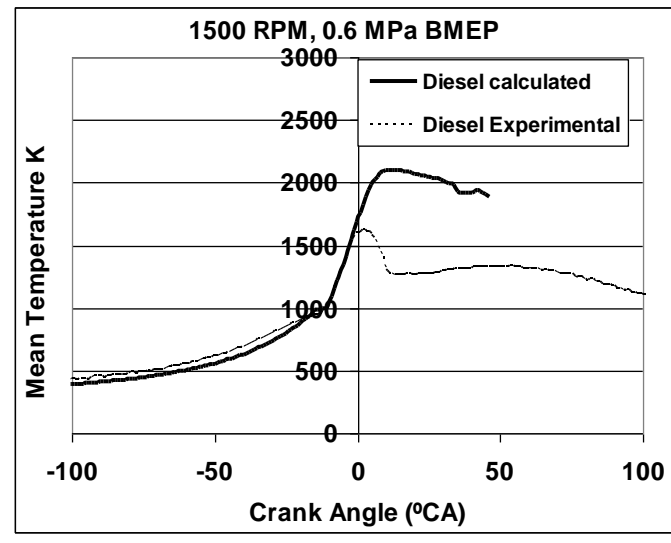

(a)

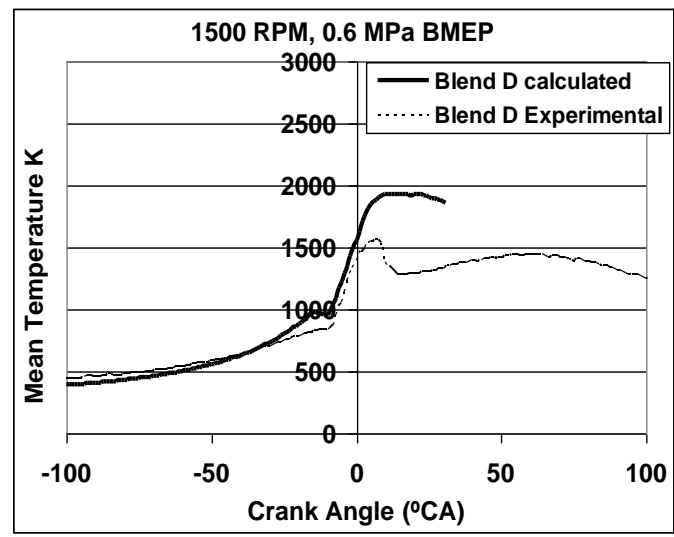

(c)

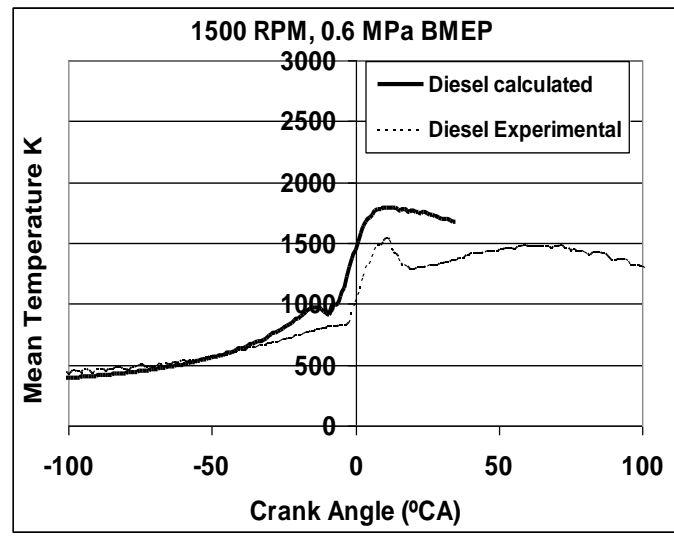

(e)

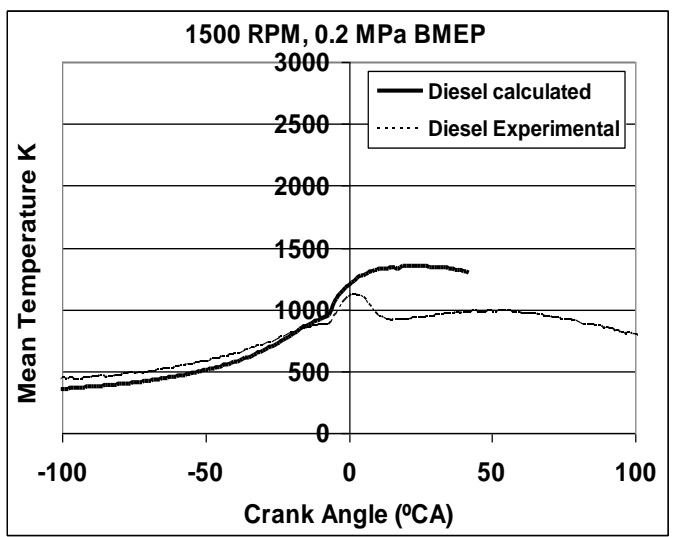

(b)

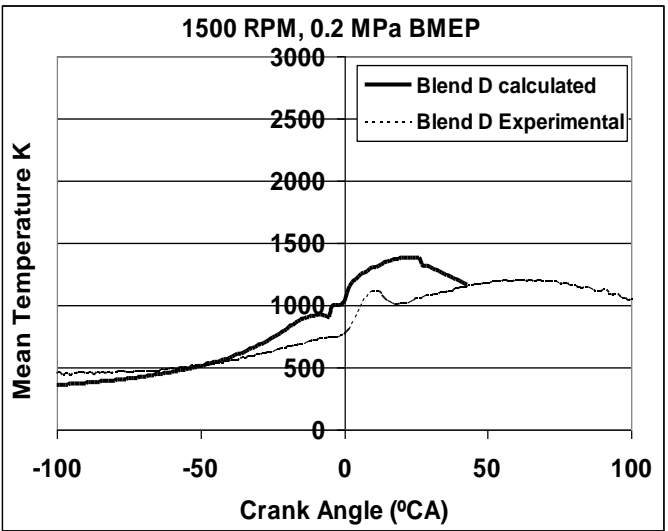

(d)

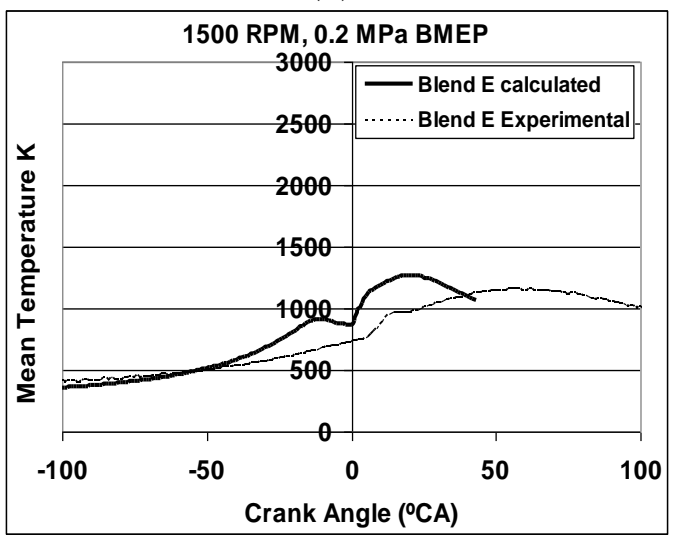

(f)

Figure 4: Mean temperature in cylinder of diesel at (a) $0.6 \mathrm{MPa}$ and (b) $0.2 \mathrm{MPa}$; blend $\mathrm{D}$ at (c) $0.6 \mathrm{MPa}$ and (d) $0.2 \mathrm{MPa}$; blend E, at (e) $0.6 \mathrm{MPa}$ and (f) $0.2 \mathrm{MPa}$ load. 


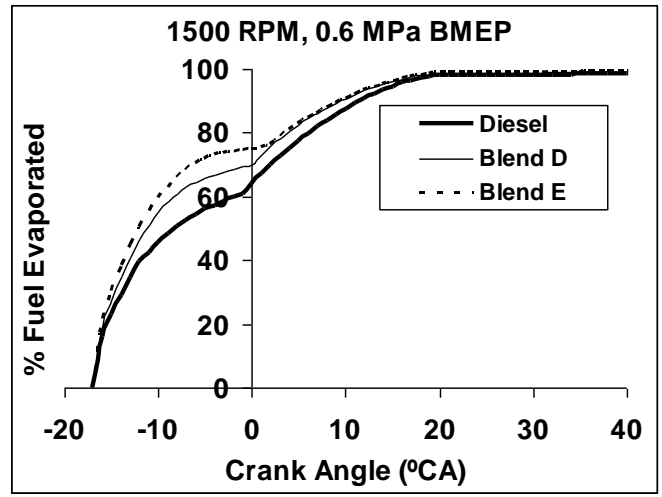

(a)

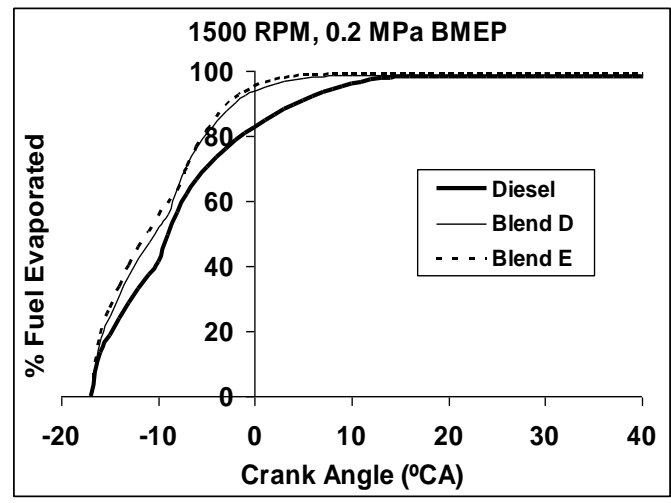

(b)

Figure 5. Time history of percentage of fuel evaporated of different fuels at (a) at 0.6 $\mathrm{MPa}$ and (b) $0.2 \mathrm{MPa}$ load.

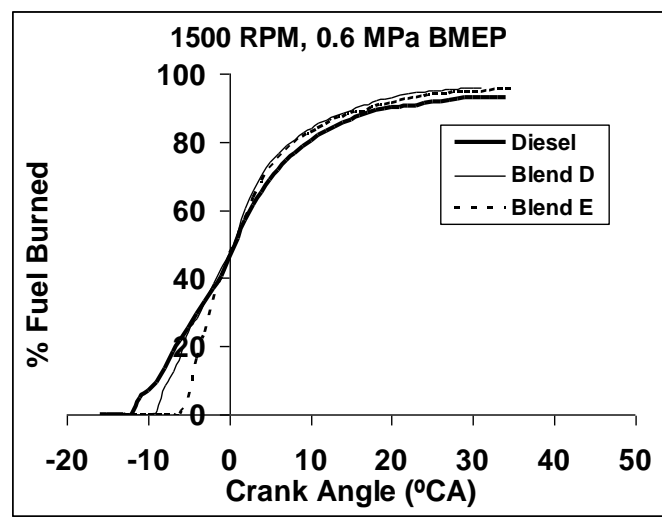

(a)

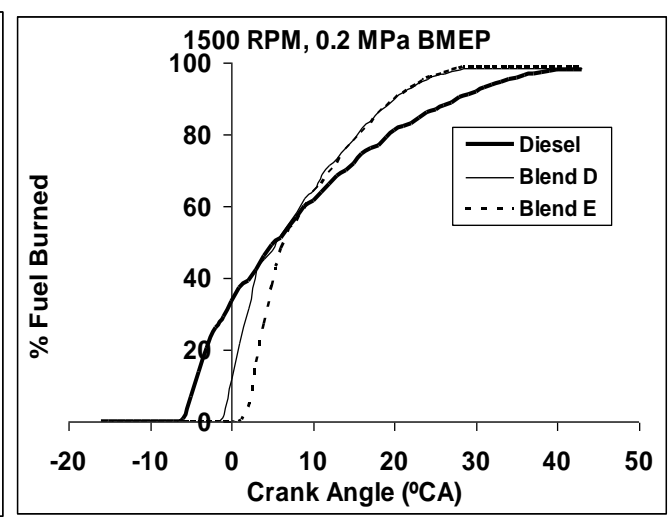

(b)

Figure 6. Time history of percentage of fuel burned for different fuels at (a) $0.6 \mathrm{MPa}$ and (b) $0.2 \mathrm{MPa}$ load.

\section{Sauter Mean Diameter}

Graphs (a) to (b) from Figure 7 shows that droplet size (Sauter mean diameter) is decreased for the blends $\mathrm{E}$ and $\mathrm{D}$ compared to diesel fuel indicating that the atomization of fuel during injection is improved for the DEB blends of high ethanol fraction. This is attributed basically to the lower density, viscosity and surface tension of the DEB blends compared to diesel fuel. The improved atomization in addition to the marginal increase in spray cone angle leads to the improved air fuel mixing for the blends D and E compared to diesel fuel. The decreased SMD also leads to the increase in the rate of fuel evaporation.

The results also show that the dynamic injection timings at both loads for diesel fuel, blend D and blend E is $17.095^{\circ} \mathrm{CA}$ BTDC, $17.043^{\circ} \mathrm{CA}$ BTDC and $16.872^{\circ} \mathrm{CA}$ $\mathrm{BTDC}$ respectively. The static injection timing of the engine is $21^{\circ} \mathrm{CA}$ BTDC. This shows marginal delayed initiation of injection for the blends against the diesel fuel, attributed to its lower density and bulk modules of elasticity. In addition, the little lower injection velocities of the blends than the diesel fuel (also attributed to the lower densities and bulk modules) contribute to this end too. 


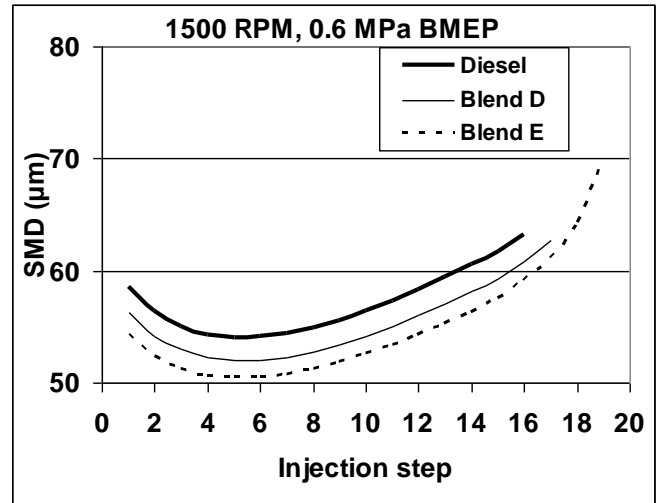

(a)

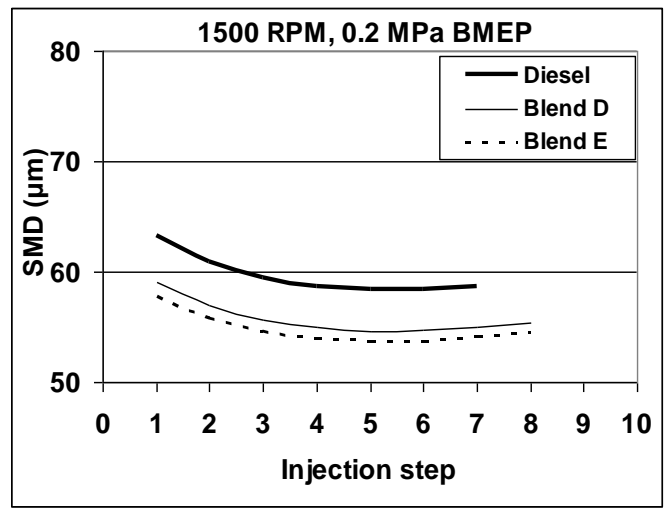

(b)

Figure 7. Sauter mean diameter of fuel droplets at the time of spray break-up at (a) $0.6 \mathrm{MPa}$ and (b) $0.2 \mathrm{MPa}$ load.

It is also observed that the injection duration at $0.6 \mathrm{MPa} \mathrm{BMEP}$ is $16^{\circ} \mathrm{CA}$ for diesel fuel and $17^{\circ} \mathrm{CA}$ for blend $\mathrm{D}$ and $19^{\circ} \mathrm{CA}$ for blend $\mathrm{E}$ as higher quantity of blend is to be injected to get the same power. Therefore, numbers of zones in the direction of spray are 16 for diesel, 17 for blend D and 19 for blend E. Similarly, the injection duration at 0.2 $\mathrm{MPa} \mathrm{BMEP}$ is $6^{\circ} \mathrm{CA}, 7^{\circ} \mathrm{CA}$ and $8^{\circ} \mathrm{CA}$ for diesel fuel, blend $\mathrm{D}$ and blend $\mathrm{E}$ respectively.

It is also noticed that the increased number of injection steps at high loads for DEB blends observed less injection pressure for the end parcels. This has reduced the quantity of fuel injected at the end of injection process and put the limitations on the peak power generation of the engine.

\section{Temperature Distribution in the Zones}

Graph (a) to (b) from Figure 8 shows mean value of temperature in the zone at different instant of time. The sudden increase of the temperature with the initiation of combustion can also be observed. After the ignition delay period, for the two fuels, combustion initiates at the jet tip and the periphery where the conditions are within the ignition limits and close to Stoichiometry, a fact that is in agreement with published experimental data from pictures taken inside the combustion chamber [1]. As time elapses, combustion is spread inside the jet and moves towards the injection nozzle (refer Plots (a) to (f) from figure 9)

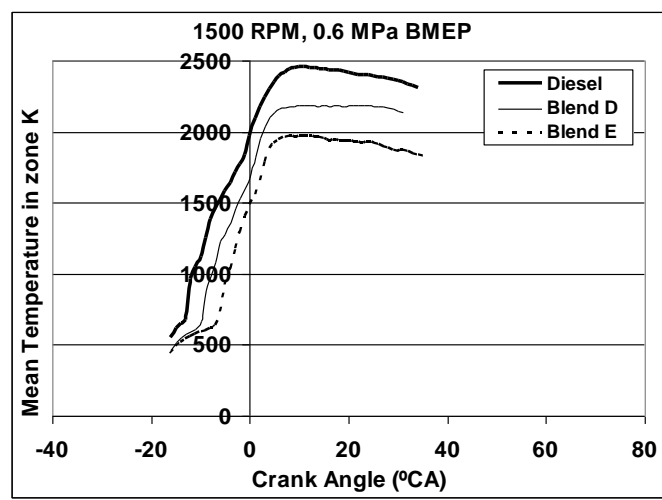

(a)

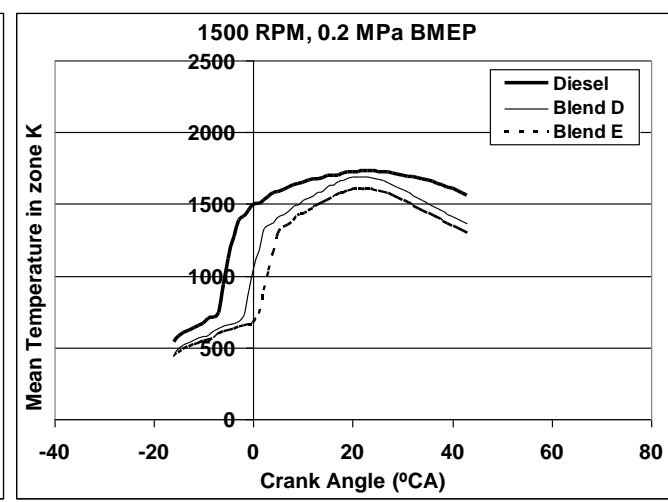

(b)

Figure 8. Mean temperature in the fuel zone at (a) $0.6 \mathrm{MPa}$ and (b) $0.2 \mathrm{MPa}$ load. 
Graph (a) to (b) from Figure 9 shows the mean temperature in the zone is significantly lower for blend D and E compared to diesel fuel. This is attributed to the fact of high latent heat of evaporation $(474 \mathrm{~kJ} / \mathrm{kg}$ for blend E, 412 for blend D and 250 $\mathrm{kJ} / \mathrm{kg}$ for diesel fuel) and decreased calorific value [10] of the blend D and E compared to diesel fuel. Engine running little leaner also contributes to this end. Significant decreased temperature in the zone for DEB blends of high ethanol fraction proves the major role played by higher ethanol during the combustion process of diesel engine.

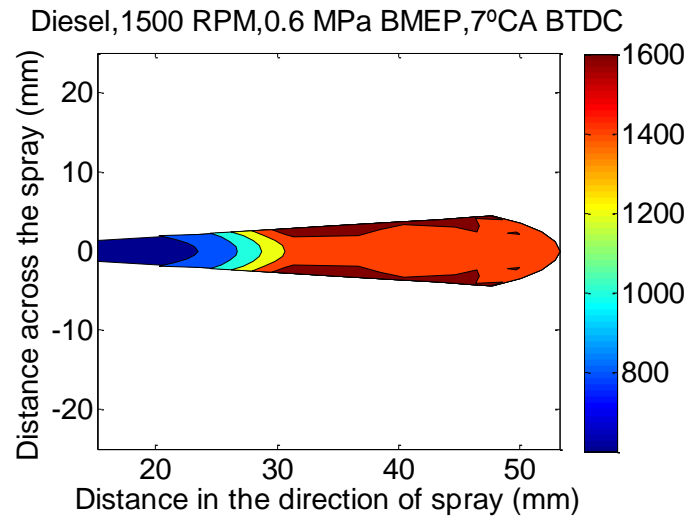

(a) mean temp $=1268 \mathrm{~K}$

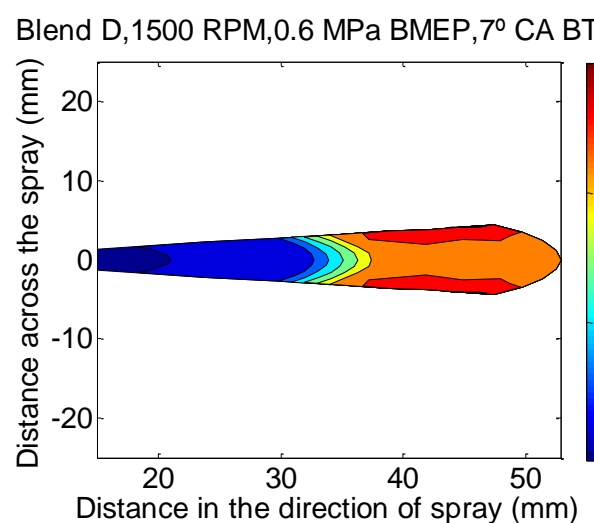

(c) mean temp $=1138 \mathrm{~K}$

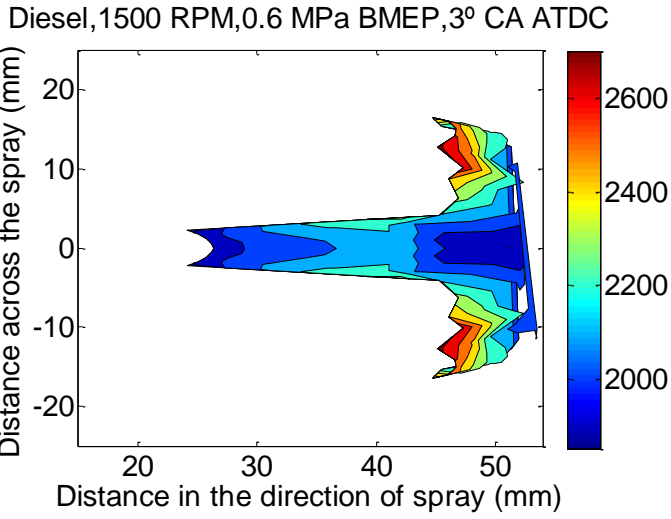

(b) mean Temp $=1827 \mathrm{~K}$
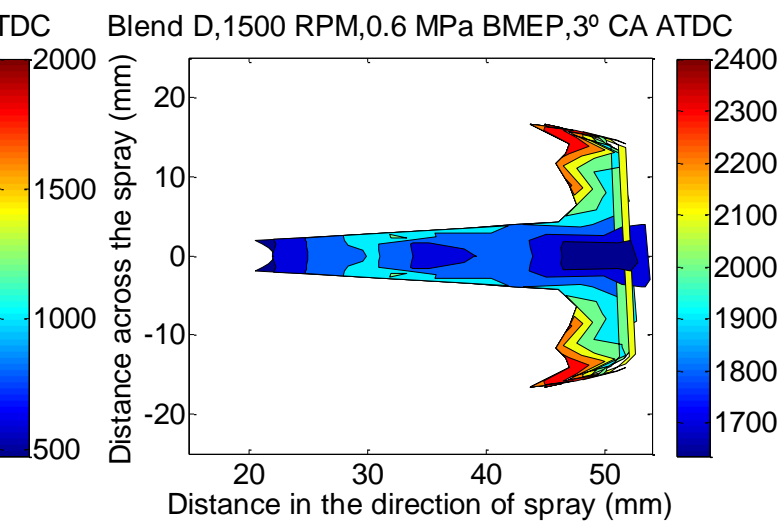

(d) mean temp $=1705 \mathrm{~K}$

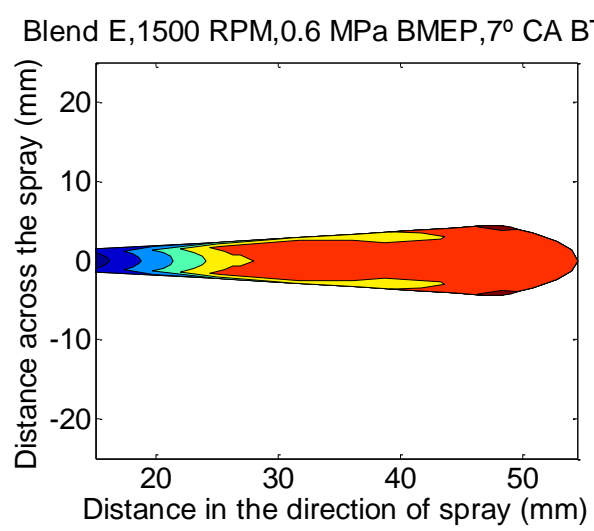

(e) mean temp $=1000 \mathrm{~K}$

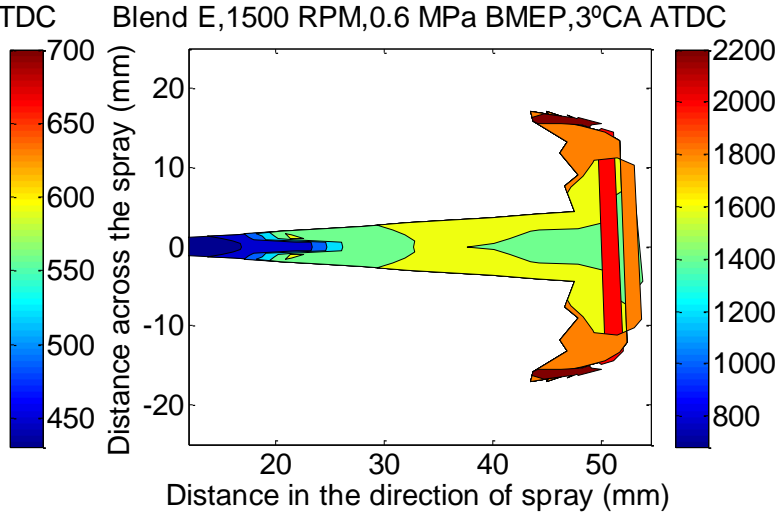

(f) mean temp $=1577 \mathrm{~K}$

Figure 9. Iso contour plots for temperature distribution in the spray of diesel at (a) 0.6 $\mathrm{MPa}$ load, $7^{\circ} \mathrm{CA}$ BTDC and (b) $0.6 \mathrm{MPa}$ load, $3^{\circ} \mathrm{CA}$ ATDC; blend D at (c) $0.6 \mathrm{MPa}$ load, $7^{\circ} \mathrm{CA}$ BTDC and (d) $0.6 \mathrm{MPa}$ load, $3^{\circ} \mathrm{CA}$ ATDC; blend E, at (e) $0.6 \mathrm{MPa}$ load, $7^{\circ} \mathrm{CA} \mathrm{BTDC}$ and (f) $0.6 \mathrm{MPa}$ load $3^{\circ} \mathrm{CA}$ ATDC. 


\section{Equivalence Ratio Distribution in the Zones}

Graph (a) to (b) from Figure 10 shows mean value of equivalence ratio in the zone at different instant of time. It is observed that the equivalence ratio in the zone is decreased for blend $\mathrm{D}$ and $\mathrm{E}$ compared to diesel fuel proving that engine runs leaner on DEB blends compared to diesel fuel. This is mainly due to improved atomization and mixing of air and fuel. The fuel bound oxygen of ethanol and biodiesel have also contributed to this end. Figure 10 show that equivalence ratio trend is not uniform as it depends on the combination of the rate of fuel evaporation, rate of air entrainment and rate of burning.

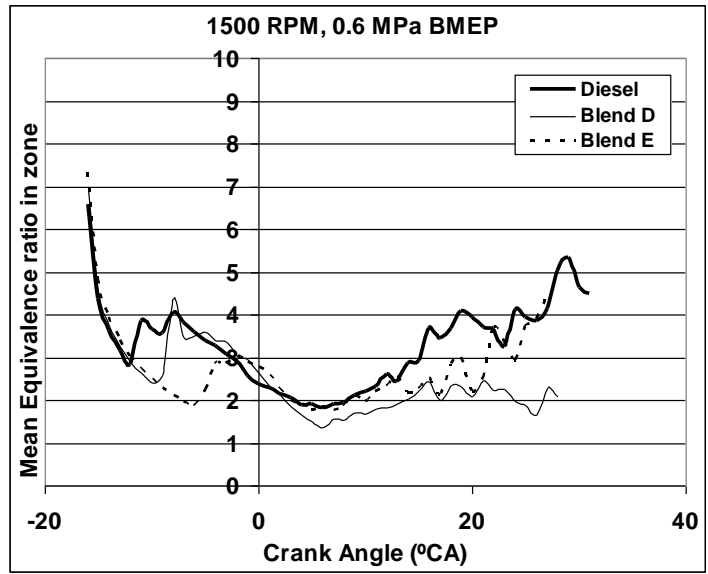

(a)

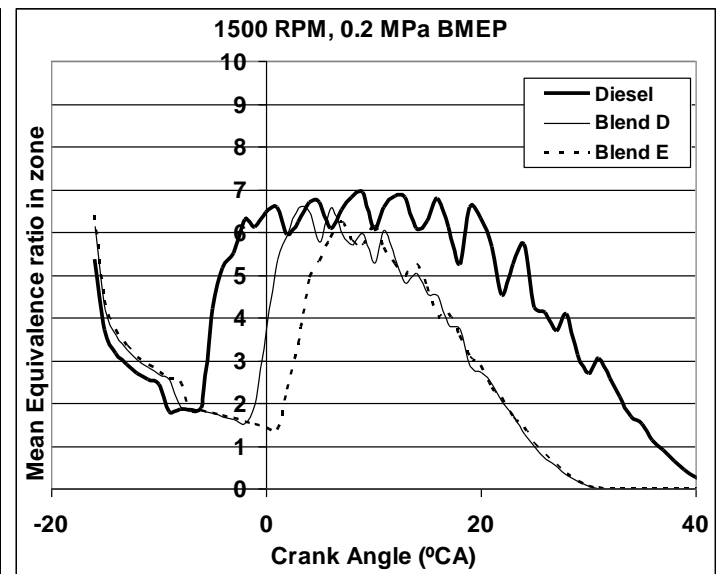

(b)

Figure 10. Mean equivalence ratio in the zone of different fuels at (a) $0.6 \mathrm{MPa}$ and (b) $0.2 \mathrm{MPa}$ load

\section{Soot Emission Distribution in the Zones}

Graph (a) to (b) from Figure 11 shows mean value of soot emission in the zone at different instant of time. It is observed that the soot density is remarkably decreased for blend $\mathrm{D}$ and $\mathrm{E}$ compared to diesel fuel at different instant of time as observed experimentally also. The lower soot density values of blend $\mathrm{D}$ and $\mathrm{E}$ with respect to the diesel fuel are attributed to the following two reasons. First, the formation of soot for blend $\mathrm{D}$ and $\mathrm{E}$ is lower due to fewer precursors formed and, second, the oxidation of soot is higher owing to the fuel bound oxygen in the ethanol as well as engine running leaner on DEB blends (refer to Figure 10).

Observing the various instants of time displayed in Figure 12 (a) to (f), it is seen that soot begins to form at the jet tip and close to the jet axis where the local zones are rich in evaporated fuel. This is in accordance with published data, where the areas close to the axis and the injector (jet core) are very rich in fuel vapor that lead to breakdown (pyrolysis) reactions of the fuel, which will later on proceed to the formation of soot. Outer zones getting more air showed lower soot density compared to central zones in both cases. Visible soot is first observed in the periphery of these areas where combustion initiates because of the high local temperatures. At $0.2 \mathrm{MPa}$ BMEP net soot formed for DEB blends is negligible as observed in the experimental results. 

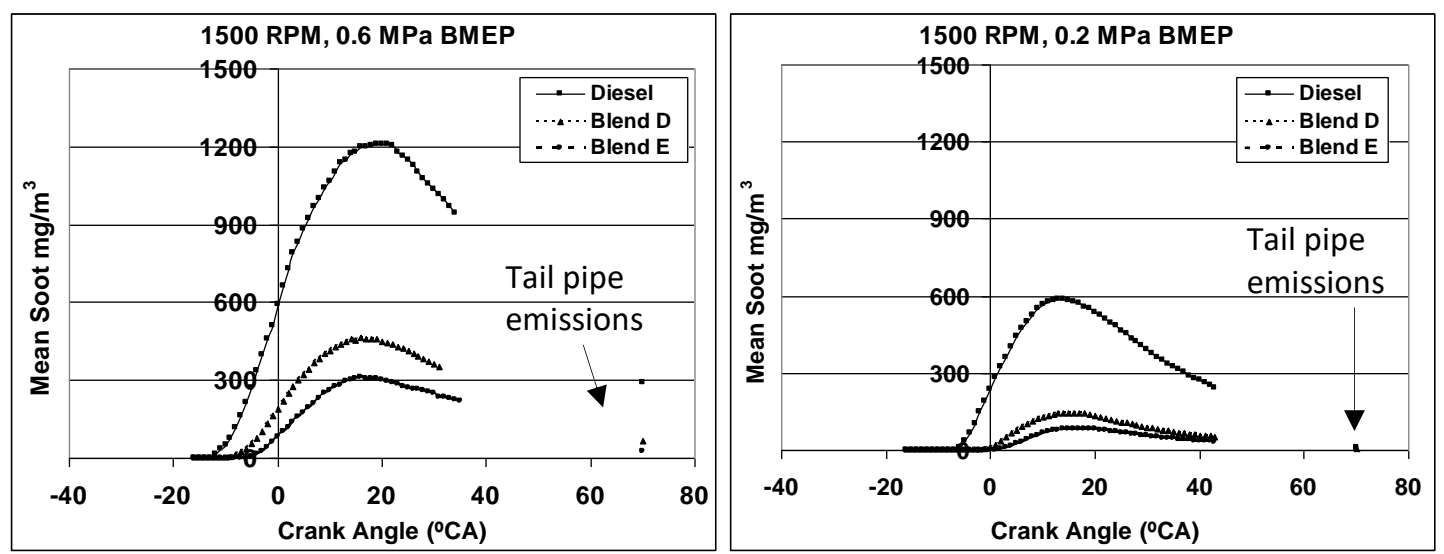

Figure 11. Mean soot in the zones of fuels at (a) $0.6 \mathrm{MPa}$ and (b) $0.2 \mathrm{MPa}$ load.

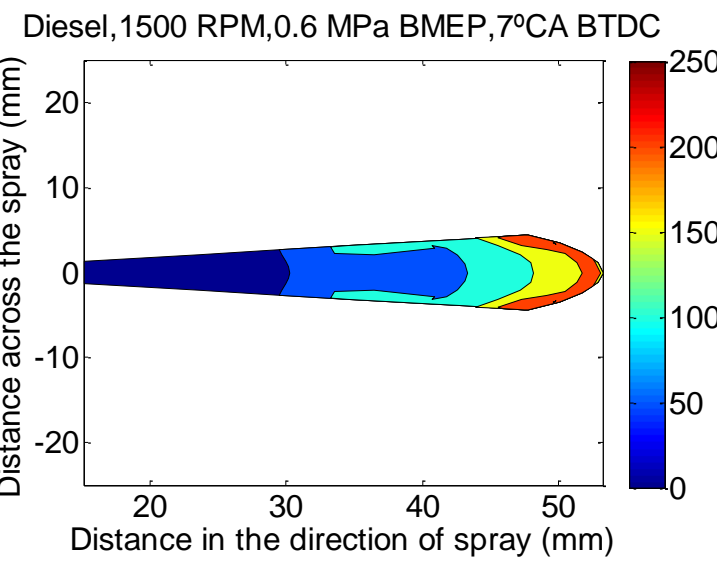

(a) mean soot $=137 \mathrm{mg} / \mathrm{m}^{3}$

Blend D,1500 RPM,0.6 MPa BMEP,7ํㅡ BTDC

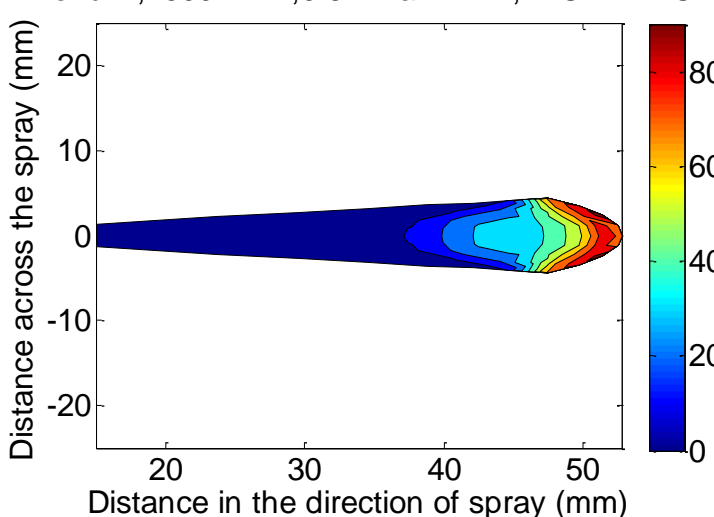

(c) mean soot $=27 \mathrm{mg} / \mathrm{m}^{3}$
Diesel, 1500 RPM,0.6 MPa BMEP, $3^{\circ}$ CA ATDC

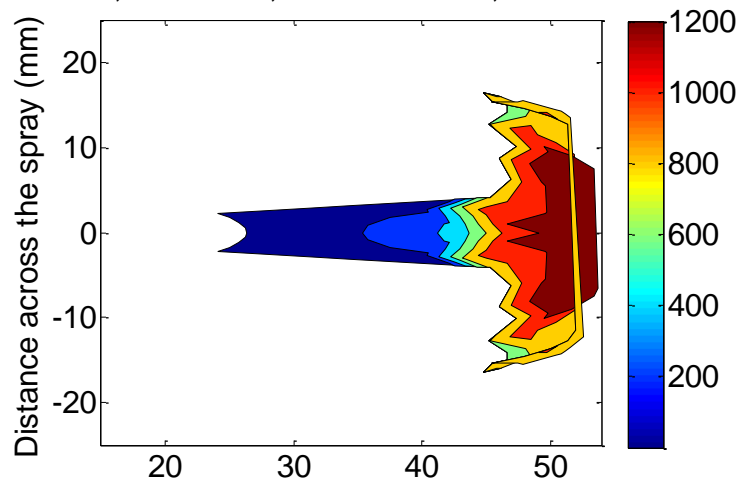

Distance in the direction of spray $(\mathrm{mm})$

(b) mean soot $=728 \mathrm{mg} / \mathrm{m}^{3}$

Blend D,1500 RPM,0.6 MPa BMEP,3 CA ATDC

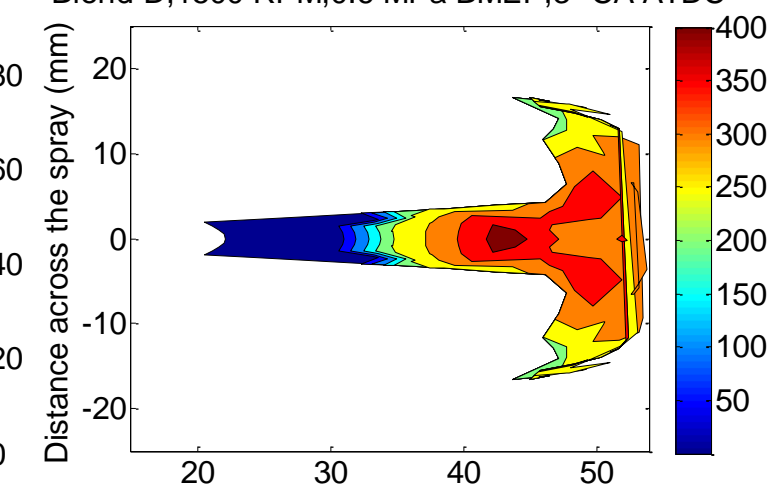

Distance in the direction of spray $(\mathrm{mm})$

(d) mean soot $=250 \mathrm{mg} / \mathrm{m}^{3}$ 
Blend E,1500 RPM,0.6 MPa BMEP,7ํㅡㄹ BTDC

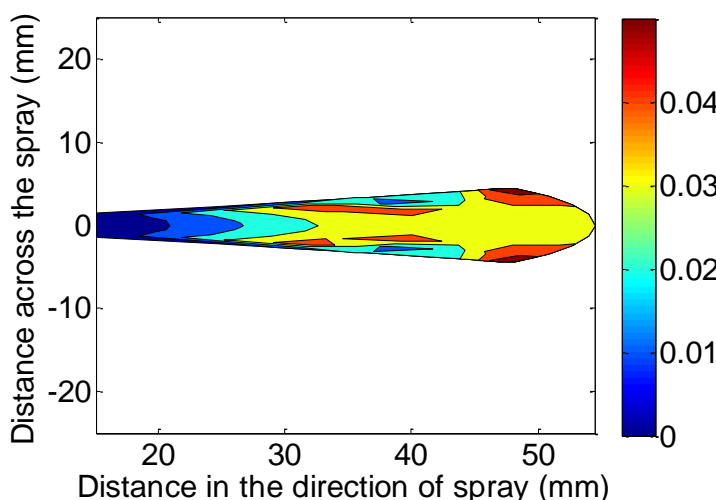

(e) mean soot $=0 \mathrm{mg} / \mathrm{m}^{3}$
Blend E,1500 RPM,0.6 MPa BMEP,3CA ATDC

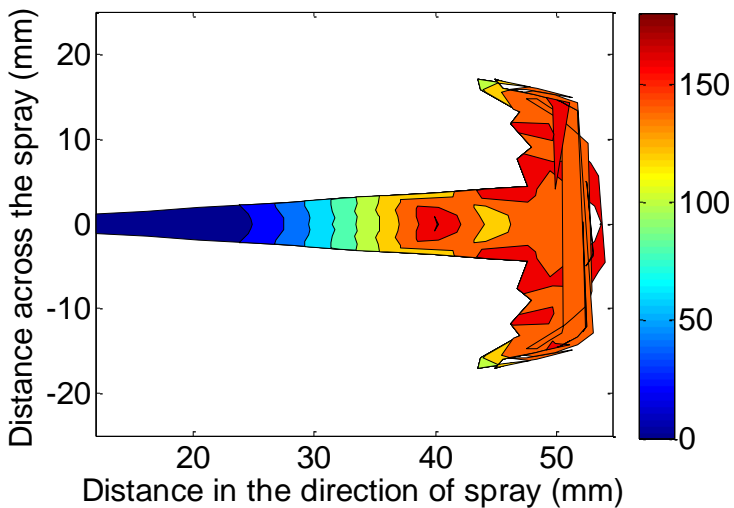

(f) mean soot $=115 \mathrm{mg} / \mathrm{m}^{3}$

Figure 12: Iso contour plots, soot distribution in the spray of $1500 \mathrm{RPM}, 0.6 \mathrm{MPa}$ BMEP of diesel at (a) $0.6 \mathrm{MPa}$ load, $7^{\circ} \mathrm{CA}$ BTDC and (b) $0.6 \mathrm{MPa}$ load, $3^{\circ} \mathrm{CA}$ ATDC; blend D at (c) $0.6 \mathrm{MPa}$ load, $7^{\circ} \mathrm{CA}$ BTDC and (d) $0.6 \mathrm{MPa}$ load, $3^{\circ} \mathrm{CA}$ ATDC; blend $\mathrm{E}$ at (e) 0.6 $\mathrm{MPa}$ load, $7^{\circ} \mathrm{CA}$ BTDC and (f) $0.6 \mathrm{MPa}$ load, $3^{\circ} \mathrm{CA}$ ATDC.

\section{NO Emission Distribution in the Zones}

Graph (a) to (b) from Figure 13 shows mean value of NO emission in the zone at different instant of time. It shows that the NO formation is drastically decreased for blends E and D compared to diesel fuel. This is mainly due to decreased temperature in the zone for DEB blends. It can also have concluded form the Figure 13 that, NO emission prediction is not so close to the experimental results especially for the DEB blends at high load as its formation is controlled both chemically and kinetically. Since crank-angle resolved measurements of pollutant concentrations are generally not available, therefore comparison of the predicted NO profile throughout the cycle with measurements was not possible. Simulation enables us to obtain this information and further line of action can be decided to reduce NO emissions.
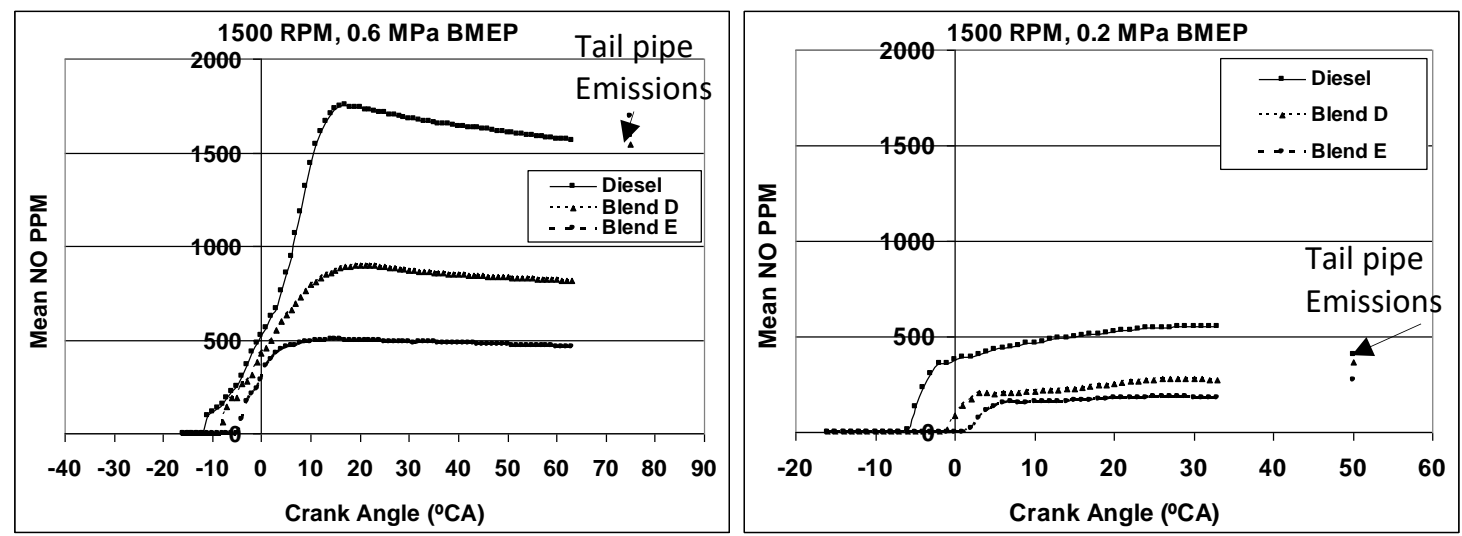

Figure 13. Mean NO concentration in the zones of different fuels at (a) $0.6 \mathrm{MPa}$ and (b) $0.2 \mathrm{MPa}$ load. 


\section{CONCLUSION}

In this paper, a closed cycle, two dimensional, multizone engine simulation model is developed and validated for DI diesel engine. The useful information related to spray formation, atomization, fuel evaporation, fuel burning and species formation is explored for diesel fuel and DEB blends of high ethanol fraction. The model study showed improved atomization with Sauter mean diameter decreased by $10 \%$ and improved mixing with air where equivalence ratio decreased by $40 \%$ for DEB blends compared to diesel fuel. It also showed that during the combustion process there is increased rate of evaporation and burning, remarkable reduction in soot formation with reduction of more than $75 \%$ and considerable reduction of NO emissions with reduction of more than $60 \%$ for DEB blends of high ethanol fraction (blend D and E) compared to diesel fuel. The study helped to understand the effect of widely different properties of DEB blends of high ethanol fraction on injection and combustion parameters of DI diesel engine.

\section{ACKNOWLEDGEMENT}

The authors would like to be obliged to Vishwakarma Institute of Technology for providing laboratory facilities

\section{REFERENCES}

[1] Heywood JB. Internal combustion engine fundamentals. New York: McGrawHill. 1988

[2] Stone R. Introduction to internal combustion engines. $3{ }^{\text {rd }}$ Eddtion. London Macmillan. 1999

[3] Kouremenos DA, Rakopoulos CD. The operation of a turbulence chamber diesel engine with LPG fumigation for exhaust emissions control. Forschung im Ingenieurwesen A.1986;52:185-90.

[4] Kouremenos DA, Rakopoulos CD, Kotsiopoulos PN. Comparative performance and emission studies for vapourized diesel fuel and gasoline as supplements in swirl-chamber diesel engines. Energy. 1990;15:1153-60.

[5] Rakopoulos CD, Kyritsis DC. Comparative second-law analysis of internal combustion engine operation for methane, methanol and dodecane fuels. Energy. 2001;26:705-22.

[6] Rakopoulos CD, Kyritsis DC. Hydrogen enrichment effects on the second law analysis of natural and landfill gas combustion in engine cylinders. Hydro Energy. 2006;31:1384-93.

[7] Rakopoulos CD, Scott MA, Kyritsis DC, Giakoumis EG. Availability analysis of hydrogen/natural gas blends combustion in internal combustion engines. Proceedings of the 19th international conference 'ECOS 2006', Crete, Greece, July 12-14. 2006; 2:983-90.

[8] Xiao Z, Ladommatos N, Zhao H. The effect of aromatic hydrocarbons and oxygenates on diesel engine emissions. 2000; 214: 307-32.

[9] Rakopoulos CD, Hountalas DT, Zannis TC, Levendis YA. Operational and environmental evaluation of diesel engines burning oxygen-enriched intake air or oxygen-enriched fuels: a review. SAE Paper. 2004-01-2924. 
[10] Hulwan DB, Joshi SV. Performance, emission and combustion characteristic of a multicylinder DI diesel engine running on diesel-ethanol-biodiesel blends of high ethanol content. Applied Energy.2011;88: 5042-5055.

[11] Assanis DN, Heywood JB.Development and Use of a Computer Simulation of the Turbo compounded Diesel System for Engine Performance and Component heat transfer studies. SAE Paper. 860329.

[12] Krieger, RB, Borman GL. The Computation of Apparent Heat Release from Internal Combustion Engines.American Society of Mechanical Engineers.1966; 66-WA/DGP-4

[13] Foster DE. An overview of zero-dimensional thermodynamic models for I.C. engine data analysis. SAE Paper. 852070

[14] Oran ES, Boris JP. Detailed modeling of combustion systems.Progress in Energy and Combustion Science. 1981;7:01-72.

[15] Bracco FV. Modeling of Engine Sprays. SAE Paper 850394

[16] Amsden AA, Ramshaw JD, O'Rourke PJ, Dukowicz JK. KIVA: A Computer Program for two- and three-dimensional fluid flow with chemical reactions and fuel sprays. Los Alamos National Laboratory Report. 1985; LA-10245-MS.

[17] Amsden AA, Butler TD, O'Rourke PJ.KIVA-II Computer Program for transient multidimensional chemically reactive flows with sprays.SAE Paper. 872072

[18] Patterson MA, Kong SC, Hampson GJ, Reitz RD. Modeling the effects of fuel injection characteristics on diesel engine soot and NOx emissions. SAE Paper. 940523.

[19] Varnavas C,Assanis DN. A high temperature and high pressure evaporation model for the KIVA-3 Code. SAE Paper. 960629.

[20] Austen AEW, Lyn WT. Some Steps Toward Calculating Diesel Engine Behavior. SAE Paper 409A, 1961.

[21] Whitehouse ND, Sareen BK. Prediction of heat release in a quiescent chamber diesel engine allowing for fuel/air mixing. SAE Paper. 740084.

[22] Hiroyasu H,Kadota T. Models for combustion and formation of Nitric Oxide and Soot in direct injection diesel engines. SAE Paper. 760129.

[23] Hiroyasu H, Kadota T, Arai M. Development and use of a spray combustion modeling to predict diesel engine efficiency and pollutant emissions (Part 1 Combustion Modeling). Bulletin of the JSME. 1983a; 26(214): 569-575.

[24] Hiroyasu H, Kadota T, Arai M. Development and use of a spray Combustion modeling to predict diesel engine efficiency and pollutant emissions (Part 2Computational Procedure and Parametric Study).Bulletin of the JSME. 1983b; 26(214): 576-583.

[25] Yoshizaki T, Nishida K, Hiroyasu H. Approach to low NOx and smoke emission engines by using phenomenological simulation. SAE Paper. 930612.

[26] Rakopoulos CD,Antonopoulos KA, Rakopoulos DC. Development and application of multi-zone model for combustion and pollutants formation in direct injection diesel engine running with vegetable oil or its bio-diesel. Energy Conversion and Management. 2007;48:1881-1901.

[27] Rakopoulos CD,Antonopoulos KA, Rakopoulos DC, Hountalas DT. Multi-zone modeling of combustion and emissions formation in DI diesel engine operating on ethanol-diesel fuel blends. Energy Conversion and Management.2008;49: 625-643. 
[28] RakopoulosCD,Antonopoulos KA, Rakopoulos DC.Multi-zone modeling of Diesel engine fuel spray development with vegetable oil, bio-diesel or Diesel fuels. Energy Conversion and Management. 2006; 47: 1550-1573. 